Journal of Engineering Science, Vol. 17(2), 19-29, 2021

\title{
Green Synthesis of Iron Oxide Nanoparticle Using Coffee Seed Extract and Its Antibacterial Activity
}

\author{
Yi Peng Teoh ${ }^{1}$, Zhong Xian Ooi ${ }^{2,3 *}$, Sim Siong Leong ${ }^{1}$, Pao Tyon $\mathrm{Ng}^{4}$ and Wei \\ Wen $\mathrm{Liu}^{5}$
}

${ }^{1}$ Department of Petrochemical Engineering, Faculty of Engineering and Green Technology, Universiti Tunku Abdul Rahman, Jalan Universiti, Bandar Barat, 31900 Kampar, Perak, Malaysia

${ }^{2}$ Department of Chemical Science, Faculty of Science, Universiti Tunku Abdul Rahman, Jalan Universiti, Bandar Barat, 31900 Kampar, Perak, Malaysia

${ }^{3}$ Centre for Photonics and Advanced Materials Research, Universiti Tunku Abdul Rahman, Jalan Universiti, Bandar Barat, 31900 Kampar, Perak, Malaysia ${ }^{4}$ Faculty of Engineering Technology, Universiti Malaysia Perlis (UniMAP), P.O. Box 77, D/A Pejabat Pos Besar, 01000 Kangar, Perlis, Malaysia ${ }^{5}$ Institute of Nano Electronic Engineering, Universiti Malaysia Perlis (UniMAP), P.O. Box 77, D/A Pejabat Pos Besar, 01000 Kangar, Perlis, Malaysia

*Corresponding author: ooizx@utar.edu.my

Published online: 15 December 2021

To cite this article: Yi Peng Teoh, Zhong Xian Ooi, Sim Siong Leong, Pao Tyon Ng and Wei Wen Liu (2021). Green synthesis of iron oxide nanoparticle using coffee seed extract and its antibacterial activity. Journal of Engineering Science, 17(2), 19-29, https://doi. org/10.21315/jes2021.17.2.2.

Link to article: https://doi.org/10.21315/jes2021.17.2.2

\begin{abstract}
The discovery of reliable and green processes for metal oxide nanoparticles synthesis is particularly crucial and exhibits huge potential in various applications. Thus, in this paper, a fast, single step and environmental-friendly method to synthesize iron oxide nanoparticles $\left(\mathrm{Fe}_{2} \mathrm{O}_{3}-\mathrm{NPS}\right)$ by bio-reduction of iron salts $\mathrm{Fe}^{2+}$ and $\mathrm{Fe}^{3+}$ under the presence of coffee seeds (CS) aqueous extract was demonstrated. The characteristics of the synthesised $\mathrm{Fe}_{2} \mathrm{O}_{3}$-NPS were investigated by using X-ray diffraction (XRD) and ultraviolet-visible (UV-Vis) spectrophotometry techniques. The XRD result revealed that the $\mathrm{Fe}_{2} \mathrm{O}_{3}$-NPs produced display highly crystalline property with a cubic structure and the average size of the resulted particle is ranging from $23.2 \mathrm{~nm}$ to $37.5 \mathrm{~nm}$. Additionally, the energy band gap $\left(E_{g}\right)$ calculated also showed that maghemite $\left(\gamma-\mathrm{Fe}_{2} \mathrm{O}_{3}\right)$ nanoparticles was successfully synthesised by using CS extract. The resulted nanoparticles are highly feasible in the inhibition of the growth of pathogenic microorganism.
\end{abstract}

Keywords: antibacterial activity, coffee seed extract, iron oxide, nanoparticles 


\section{INTRODUCTION}

Nanoscale technology products have very different physical and chemical properties as compared to their bulk counterparts. New research on the synthesis of metal nanoparticles may lead to their widespread potential applications in the biomedical (e.g., imaging, therapy, disease diagnosis and treatment), environmental and electronics fields. ${ }^{1,2}$ Iron oxide nanoparticles can be applied to cancer diagnosis, drug delivery, electrochemical devices, magnetic resonance imaging, and etc. Iron oxide nanoparticles are also being used to remove arsenic, dye, microalgae, heavy metal and etc. from water through a magnetophoresis process, and this method is found to be cheaper than conventional water treatment methods, such as reverse osmosis (RO) and anionic exchange methods. ${ }^{3}$

Up to the current stage, synthesis of metal nanoparticles via physicochemical $^{4-7}$ and biological ${ }^{8,9}$ approaches has been well established to synthesise metal nanoparticles; however, each approach has its own drawbacks. The most common concerns for evaluating the nanoparticle synthesis methods include time, cost of materials, labour intensity, and environmental impact. During the physicochemical process, chemical reagent such as sodium borohydride $\left(\mathrm{NaBH}_{4}\right)$ is used as a reducing agent for the reduction of $\mathrm{Fe}^{3+}$ ions; while ethanol $\left(\mathrm{C}_{2} \mathrm{H}_{6} \mathrm{O}\right)$ is normally employed to prohibit the rapid oxidation of $\mathrm{Fe}^{2+}$ ions. ${ }^{10}$ The simultaneous utilisation of two chemicals in a process causes the increment in the production cost. At the same time, these two chemicals also exhibit a hazardous effect which may adversely affect the nervous system. The biological method, in which microorganisms are employed to synthesise metal nanoparticles, often requires a longer time to incubate bacteria, and this method can significantly delay the synthesis process. ${ }^{11}$ Therefore, it is crucial to develop a nanoparticle synthesis method that is low-cost, fast and environmentally friendly. In this regard, the single step and green synthesis of iron oxide nanoparticles using plant extracts appears to be one potential candidate and can be advantageous over other conventional synthesis methods that have been well-established. In fact, plant extracts, such as Caricaya papaya leaves, ${ }^{10}$ seaweed, ${ }^{12}$ and Desmodium gangeticum ${ }^{9}$ have been revealed to be feasible to synthesise iron oxide nanoparticles.

Coffee is the second commodity mostly traded in the world after petroleum. Malaysia was ranked $60^{\text {th }}$ worldwide, which contributes $0.16 \%$ of the world's coffee production. In Malaysia, the planted area are nearly 3,760 hectares which produce 14,739 tons coffee in year $2013 .{ }^{13}$ Coffee contains several bioactive substances, including polysaccharides, saponins, alkaloids, flavonoids, steroids, and phenols. ${ }^{14}$ These phytochemicals, which present in coffee seed (CS) extract, serve dual roles as metal reducing agents and capping agents during iron oxide 
nanoparticle synthesis, thus, they are the critical reagent in the conversion of iron ions to iron atoms that are acting as the building blocks of iron oxide nanoparticles.

Escherichia coli (E. coli) and Staphylococcus aureus (S. aureus) are the most common human pathogens. Some $S$. aureus strains are resistant to antibiotics such as vancomycin, penicillin, methicillin, tetracycline, and erythromycin. ${ }^{15}$ Iron oxide nanoparticles are promising antibacterial agents to combat human pathogens. To date, there is no study that examines the effect of CS extract-mediated iron oxide nanoparticles on human pathogens. In this research, iron oxide nanoparticles were synthesised by using aqueous CS extract. The crystalline structure of the assynthesised iron oxide nanoparticles was characterised by using X-ray diffraction and UV-Vis spectrophotometry. Last but not least, the antibacterial activity of the synthesised iron oxide nanoparticles towards two very common bacteria ( $E$. coli and $S$. aureus) was examined.

\section{MATERIALS AND METHODS}

\subsection{Materials}

Iron (II) chloride tetrahydrate $\left(\mathrm{FeCl}_{2} \cdot 4 \mathrm{H}_{2} \mathrm{O}\right.$; Brand: Bendozen) and iron (III) chloride hexahydrate $\left(\mathrm{FeCl}_{3} \cdot 6 \mathrm{H}_{2} \mathrm{O}\right.$; Brand: $\left.\mathrm{Hmbg}\right)$, were purchased from A.R. Alatan Sains (K) Sdn. Bhd., Alor Setar, Malaysia, and were used without further purification. Coffee seeds were collected from Kawasan Perindustrian Lahat, Perak, Malaysia. All aqueous solutions used in the nanoparticle synthesis were prepared by using distilled deionized water (DDW).

\subsection{CS Extract Preparation}

The as-received CS were first washed and then kept under the temperature of $-20^{\circ} \mathrm{C}$ before being used for nanoparticle synthesis. Next, about $9 \mathrm{~g}$ of CS samples were dissolved into $250 \mathrm{~mL}$ DDW in an Erlenmeyer flask which was then subjected to boiling under continual stirring for 30 minutes. After the boiling process, the extract (which was suspended in DDW) was cooled to room temperature. The solution is then filtered so that the extract can be collected and stored under the temperature of $-20^{\circ} \mathrm{C}$.

\subsection{Iron Chloride Solution Preparation}

To produce the iron chloride mixture solution, $\mathrm{FeCl}_{2} \cdot 4 \mathrm{H}_{2} \mathrm{O}(4.97 \mathrm{~g})$ and $\mathrm{FeCl}_{3} \cdot 6 \mathrm{H}_{2} \mathrm{O}$ $(13.52 \mathrm{~g})$ were dissolved thoroughly in $250 \mathrm{~mL}$ DDW in a beaker. 


\subsection{Iron Oxide Nanoparticles Preparation}

Iron oxide nanoparticles $\left(\mathrm{Fe}_{2} \mathrm{O}_{3}\right.$-NPs $)$ were synthesised by adding the prepared iron salts $\mathrm{Fe}^{2+}$ and $\mathrm{Fe}^{3+}$ to the CS extract (with a volume ratio of 1:1). Next, the mixture was subjected to a stirring process for a duration of 60 minutes. After the stirring process, the mixture was let standstill under room temperature for another 30 minutes. Subsequently, the mixture was centrifuged and the collected pellets were washed with ethanol for a few times before being oven-dried overnight under the temperature of $60^{\circ} \mathrm{C}$. The obtained solid was calcinated in a furnace at $500^{\circ} \mathrm{C}$ for 7 hours to obtain the $\mathrm{Fe}_{2} \mathrm{O}_{3}$-NPs. The synthesised $\mathrm{Fe}_{2} \mathrm{O}_{3}$-NPs were stored at room temperature for further analysis.

\subsection{Characterisation Methods and Instruments}

The ultraviolet-visible (UV-Vis) spectra of $\mathrm{Fe}_{2} \mathrm{O}_{3}$-NPs were measured over a wavelength range of 200 to $1200 \mathrm{~nm}$ by using Perkin Elmer Lambda $35 \mathrm{UV}$-Vis spectrophotometer (Penang, Malaysia). The crystalline structure of the resulted $\mathrm{Fe}_{2} \mathrm{O}_{3}$-NPs was examined by X-ray diffraction measurement (with model of XRD6000 , Shimadzu, Petaling Jaya, Malaysia).

\subsection{Minimum Inhibitory Concentration (MIC) Assay}

The broth microdilution assay, using a 96-well microtiter plate, was used to determine the minimum inhibitory concentration (MIC) according to the protocol of NCCLS ${ }^{16}$ with some modifications. Mycelia suspension of pathogenic microorganisms (e.g., E. coli and S. aureus) was cultivated and standardised according to $0.5 \mathrm{McF}$ arland standard turbidity. The synthesised $\mathrm{Fe}_{2} \mathrm{O}_{3}$ - $\mathrm{NPs}$ were dissolved into $5 \%$ dimethyl sulfoxide (DMSO) to obtain a solution of 1,10 , and $100 \mu \mathrm{g} / \mu \mathrm{L}$. Next, $0.09 \mathrm{~mL}$ of the $\mathrm{Fe}_{2} \mathrm{O}_{3}$-NPs solution was added into each well, and the mycelia suspension of pathogenic microorganisms was inoculated into each well to make a final volume of $0.1 \mathrm{~mL}$. Incubations were conducted under the temperature of $30^{\circ} \mathrm{C}$ for duration of 48 hours. In order to quantitatively measure the inhibition performance of the synthesised $\mathrm{Fe}_{2} \mathrm{O}_{3}-\mathrm{NPs}, 0.02 \mathrm{~mL}$ of the yellow tetrazolium MTT (3-(4,5-dimetylthylthiazolyl-2)-2,5-diphenyltetrazolium bromide) reagent was added into each well. The measurement of antibacterial activities was performed after incubating for 2 hours. The fungal growth was indicated by the blue coloration of the solution, in which a clear colour of the well indicated that growth inhibition had occurred. 
In this context, MIC indicates the smallest concentration of a substance in any sample which would completely suppress the growth of any microorganism throughout the incubation process. DMSO did not interfere with the reaction conditions within the concentration range being employed in this study. ${ }^{17}$

\section{RESULTS AND DISCUSSION}

\subsection{Ultraviolet-Visible (UV-Vis) Spectroscopy}

The light absorption spectrum of a material is crucial in providing the information about the composition/structure of the given material because the molecules in the material will undergo electronic transitions upon exposure to the incident electromagnetic wave. Figure 1 illustrates the UV-Vis absorption spectrum of $\mathrm{Fe}_{2} \mathrm{O}_{3}$-NPs in the aqueous CS extract. The absorption peak at $590 \mathrm{~nm}$ shows the existence of iron nanoparticles in the suspension. This is consistent with the research done by Sathishkumar et al., ${ }^{18}$ in which a new band at $590 \mathrm{~nm}$ attributes to the intrinsic stretching vibrations of the metal at a tetrahedral site.

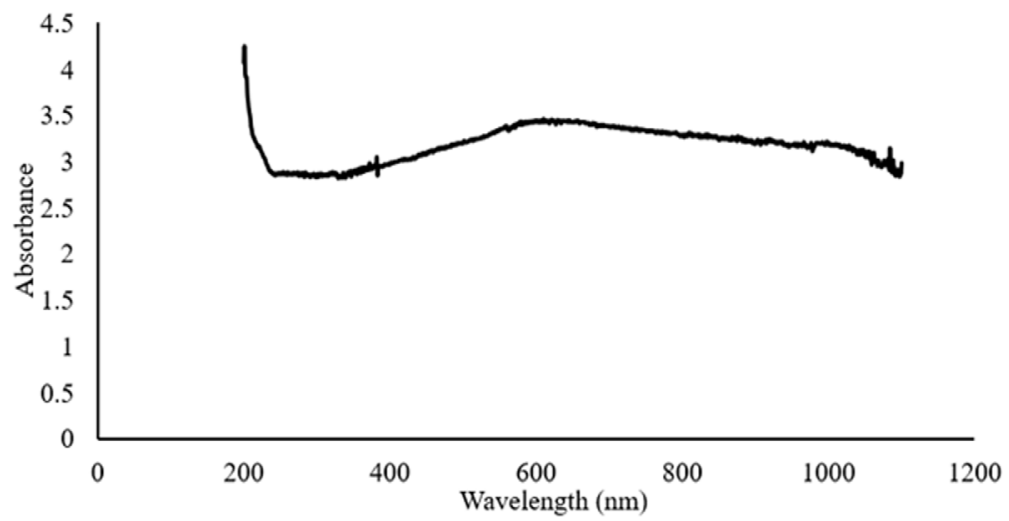

Figure 1: UV-visible absorption spectra of $\mathrm{Fe} 2 \mathrm{O} 3 / \mathrm{CS}$ extract.

Furthermore, the corresponding energy band gap of the synthesised material can be calculated using the Tauc method with Eq. 1,,$^{19,20}$

$$
(\alpha h v)^{2}=c\left(h v-E_{g}\right)
$$

where $\alpha$ is the light absorption coefficient, $h$ is Plank's constant, $v$ is the light frequency, $c$ is a constant (that is, relying on the energy carried by each photon), and $E_{g}$ is the material band gap energy. This can be estimated from the 
$(\alpha h v)^{2}$ versus the $c\left(h v-E_{g}\right)$ plot (which was obtained by transforming the data shown in Fig. 1), by extrapolating the straight part of $(\alpha h v)^{2}$ to the photon energy ( $h v$ or vertical) axis (as illustrated in Fig. 2). After calculation, the $E_{g}$ value for this $\mathrm{Fe}_{2} \mathrm{O}_{3} / \mathrm{CS}$ extract was determined to be $2.15 \mathrm{eV}$, which is denoting the energy that must be absorbed by an electron in the material such that it will be sufficiently energetic to be driven from the valence band to the conduction band. Furthermore, this result is useful to determine the interatomic distance within the tested material. Based on a report by Pavani et al., ${ }^{20}$ the $E_{g}$ range for $\gamma$ type- $\mathrm{Fe}_{2} \mathrm{O}_{3}$ is 2.0 to $2.2 \mathrm{eV}$. Hence, according to the $E_{g}$ value, it can be deduced that $\gamma-\mathrm{Fe}_{2} \mathrm{O}_{3}$ nanoparticle was being synthesised in this study.

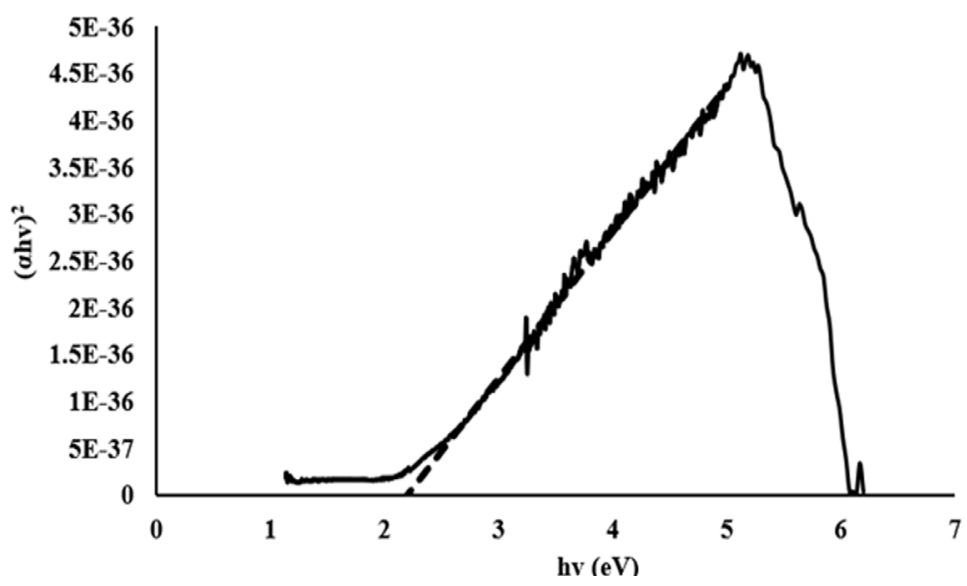

Figure 2: Graph of $(\alpha h v)^{2}$ against photon energy for $\mathrm{Fe}_{2} \mathrm{O}_{3} / \mathrm{CS}$ extract.

\subsection{X-ray Diffraction (XRD)}

In addition, XRD was used to examine the crystalline structures and phase of the synthesised nanoparticles in this study. Figure 3 shows the XRD pattern resulted from the synthesised $\mathrm{Fe}_{2} \mathrm{O}_{3}$-NPs by using CS extract. Intense diffraction peaks were identified with $2 \theta$ values of $33.3^{\circ}, 35.5^{\circ}, 40.6^{\circ}, 54.2^{\circ}, 61.4^{\circ}$, and $64.1^{\circ}$, corresponding to the crystalline $\mathrm{Fe}_{2} \mathrm{O}_{3}$-NPs crystal planes of (012), (104), (311), (400), (422), (511), and (440), respectively. These results indicate the cubic phase structure of $\gamma-\mathrm{Fe}_{2} \mathrm{O}_{3}$ and are consistent with the maghemite $\left(\gamma-\mathrm{Fe}_{2} \mathrm{O}_{3}\right)$ nanoparticles (JCPDS data 39-1356) that are taken as the reference data in this study. ${ }^{21}$

Furthermore, the average particle size of $\mathrm{Fe}_{2} \mathrm{O}_{3}$-NPs can be evaluated by using the Debye-Scherrer equation, which relates the XRD peak broadening to particle size. This equation is shown in Eq. 2:12,22 


$$
d=k \lambda /(\beta \cos \theta)
$$

where $d$ is the particle size of the crystal, $k$ is the Sherrer constant (0.9), $\lambda$ is the $\mathrm{X}$-ray wavelength $(\mathrm{Cu} \mathrm{K} \alpha$ radiation $=0.1542 \mathrm{~nm}), \beta$ is the width of the XRD peak at half-height, and $\theta$ is the Bragg diffraction angle. By applying Eq. 2, the average sizes of the $\mathrm{Fe}_{2} \mathrm{O}_{3}$-NPs crystal, synthesised by using CS extract, were in the range of 23.2 to $37.5 \mathrm{~nm}$. Thus, according to the results obtained through UV spectra XRD analysis, maghemite $\left(\gamma-\mathrm{Fe}_{2} \mathrm{O}_{3}\right)$ nanoparticles were successfully synthesised using CS extract in this study.

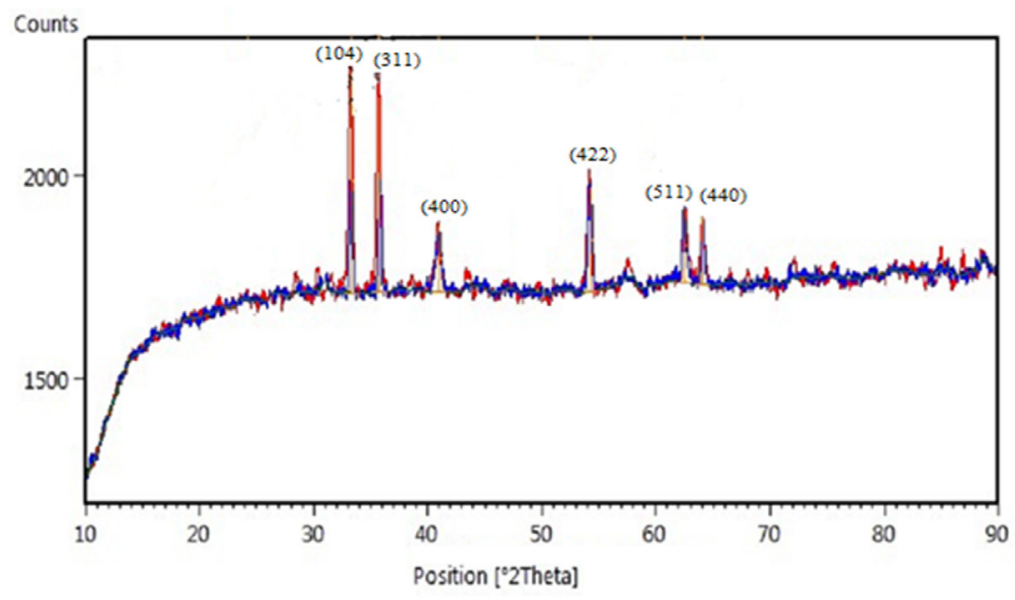

Figure 3: XRD patterns of $\mathrm{Fe}_{2} \mathrm{O}_{3}$-NPs synthesised using CS extract.

\subsection{Antibacterial Activity of Synthesised Iron Oxide Nanoparticles}

The broth microdilution assay is a testing method that is able to measure the antibacterial susceptibility of a substance quantitatively, for example, the value of MIC. ${ }^{23}$ In this study, the MIC values of $\mathrm{Fe}_{2} \mathrm{O}_{3}$-NPs were measured and defined as the minimum $\mathrm{Fe}_{2} \mathrm{O}_{3}$-NPs concentration that is able to fully inhibit the growth of microorganism, which in turn reflects their ability to suppress the growth of pathogenic bacteria. According to Table 1, the MIC of $\mathrm{Fe}_{2} \mathrm{O}_{3}$-NPs synthesised in this study to suppress the growth of $E$. coli and $S$. aureus is given by $50.00 \mu \mathrm{g} / \mu \mathrm{L}$ and $65.00 \mu \mathrm{g} / \mu \mathrm{L}$, respectively. Based on the study done by Naseem and Farrukh ${ }^{24}$, iron nanoparticle synthesised via Lawsonia inermis and Gardenia jasminoides leaves extract shows similar antibacterial activity. 
Table 1: Antibacterial activity from synthesised $\mathrm{Fe}_{2} \mathrm{O}_{3}$-NPs.

\begin{tabular}{lc}
\hline Bacteria & Minimum inhibitory concentration (MIC), $\mu \mathrm{g} / \mu \mathrm{L}$ \\
\hline Escherichia coli (E. coli) & 50.00 \\
Staphylococcus aureus (S. aureus) & 65.00 \\
\hline
\end{tabular}

According to Behera et al. ${ }^{25}$ and Mahdy et al., ${ }^{26}$ these particles suppress the growth and activity of bacteria through the oxidative stress imposed by the reactive oxygen species (ROS). This is because ROS, which comprised of superoxide radicals $\left(\mathrm{O}^{2-}\right)$, hydroxyl radicals $(-\mathrm{OH})$, hydrogen peroxide $\left(\mathrm{H}_{2} \mathrm{O}_{2}\right)$, and singlet oxygen $\left({ }^{1} \mathrm{O}_{2}\right)$, can exert detrimental effect on the activities of proteins and DNA in bacteria. For the $\mathrm{Fe}_{2} \mathrm{O}_{3}$-NPs being tested in this study, metal oxide $\left(\mathrm{Fe}_{2} \mathrm{O}_{3}\right)$ is possibly the major source of ROS that suppressed the E. coli and $S$. aureus from growing.

Furthermore, the extremely tiny physical size of the nanoparticles themselves could also be a factor that imposes anti-bacteria effects on the synthesised $\mathrm{Fe}_{2} \mathrm{O}_{3}$-NPs in this study. In fact, this phenomenon has been observed by Lee et al. ${ }^{27}$, in which $E$. coli was deactivated by iron nanoparticles because of the penetration of the particles into the $E$. coli membranes. The $\mathrm{Fe}_{2} \mathrm{O}_{3}$-NPs reacted with intracellular oxygen that causes the generation of the oxidative stress which is responsible for the damage of the membrane of the bacteria cells.

\section{CONCLUSIONS}

The study on the synthesis method of nanoparticles appears as one of the major interests in the field of science and engineering recently owing to plenty of appealing properties and versatility exhibited by the nanoparticle in various applications. Biosynthesis of iron oxide nanoparticles $\left(\mathrm{Fe}_{2} \mathrm{O}_{3}-\mathrm{NPs}\right)$ using green resources is a highly feasible approach due to its simplicity, environmentally friendly and costeffective features. In this study, $\gamma-\mathrm{Fe}_{2} \mathrm{O}_{3} \mathrm{NPs}$ were successfully synthesised through bio-reduction of iron chloride solution by using CS aqueous extract. This is proven by the UV-vis spectroscopy analysis that shows an adsorption peak at $590 \mathrm{~nm}$ and band gap energy of $2.15 \mathrm{eV}$. In addition, by applying the Debye-Scherrer equation to the XRD results, it can be revealed that the size of the synthesised NPs is ranging from $23.2 \mathrm{~nm}$ to $37.5 \mathrm{~nm}$. The synthesised $\mathrm{Fe}_{2} \mathrm{O}_{3}-\mathrm{NPs}$ also showed their great ability in antibacterial activity towards pathogenic bacteria, in which the MIC of them to suppress the growth of E. coli and $S$. aureus is given by $50.00 \mu \mathrm{g} / \mu \mathrm{L}$ and $65.00 \mu \mathrm{g} / \mu \mathrm{L}$, respectively. 


\section{ACKNOWLEDGEMENTS}

The authors gratefully acknowledge the Fundamental Research Grant Scheme (FRGS) (Grant Account No.: 9003-00528) provided by The Ministry of Higher Education (MOHE) to support this research work.

\section{REFERENCES}

1. Li, X., Xu, H., Chen, Z. S. \& Chen, G. (2011). Biosynthesis of nanoparticles by microorganisms and their applications. J. Nanomater., 2011, 8, https:// doi.org/10.1155/2011/270974.

2. Rahman, M. M., Aisiri, A. M., Jamal, A., Faisal, M., \& Khan, S. B. (2011). Iron oxide nanoparticles. In M. M. Rahman (ed.), Nanomaterials. London: IntechOpen, 43-66, https://doi.org/10.5772/27698.

3. Oregon Health Authority. (2015). Drinking water program fact sheet: Recommendations for arsenic removal from private drinking water wells in Oregon. Retrieved from http://public.health.oregon.gov/ HealthyEnvironments/DrinkingWater/SourceWater/Documents/gw/ arsenicremoval.pdf on 9 March 2015.

4. Laurent, S., Forge, D., Port, M., Roch, A., Robic, C., Elst, L. V. \& Muller, R. N. (2008). Magnetic iron oxide nanoparticles: Synthesis, stabilization, vectorization, physicochemical characterizations, and biological applications. Chem. Rev., 108(6), 2064-2110, https://doi.org/10.1021/ cr068445e.

5. Wu, W., He, Q. \& Jiang, C. (2008). Magnetic iron oxide nanoparticles: Synthesis and surface functionalization strategies. Nanoscale Res. Lett., 3(11), 397, https://doi.org/10.1007/s11671-008-9174-9.

6. Kebede, A., Gholap, A. V. \& Rai, A. K. (2011). Impact of laser energy on synthesis of iron oxide nano-particles in liquid medium. World J. Nano Sci. Eng., 1(4), 89-92, https://doi.org/10.4236/wjnse.2011.14014.

7. Umer, A., Naveed, S., Ramzan, N. \& Rafique, M. S. (2012). Selection of a suitable method for the synthesis of copper nanoparticles. Nano, 7(5), 1230005, https://doi.org/10.1142/S1793292012300058.

8. Sundaram, P. A., Augustine, R. \& Kannan, M. (2012). Extracellular biosynthesis of iron oxide nanoparticles by Bacillus subtilis strains isolated from rhizosphere soil. Biotechnol. Bioprocess Eng., 17, 835-840, https:// doi.org/10.1007/s12257-011-0582-9.

9. Santoshi, V. \& Kurian, G. A. (2015). Synthesis, characterisation and biological evaluation of iron oxide nanoparticles prepared by Desmodium Gangeticum root aqueous extract. Int. J. Pharm. Pharm. Sci., 7(1), 75-80. 
10. Latha, N. \& Gowri, M. (2014). Bio synthesis and characterisation of $\mathrm{Fe}_{3} \mathrm{O}_{4}$ nanoparticles using caricaya papaya leaves extract. IJSR, 3(11), 15511556.

11. Pantidos, N. \& Horsfall L. E. (2014). Biological synthesis of metallic nanoparticles by bacteria, fungi and plants. J. Nanomed. Nanotechnol., 5(5), 1-10, https://doi.org/10.4172/2157-7439.1000233.

12. Mahdavi, M., Namvar, F., Ahmad, M. \& Mohamad, R. (2013). Green biosynthesis and characterization of magnetic iron oxide $\left(\mathrm{Fe}_{3} \mathrm{O}_{4}\right)$ nanoparticles using seaweed (Sargassum muticum) aqueous extract. Molecules, 18(5),5954-5964,https://doi.org/10.3390/molecules18055954.

13. Mohammad Nor, N. A. A. \& Abd. Wahab, M. A. M. (2016). Exploring the potentials of coffee industry in Malaysia. Retrieved from http://ap.fftc. agnet.org/ap_db.php?id=574\&print=1 on 8 September 2016.

14. Kisoi, G., Kinyua, J. \& Wamunyokoli, F. (2016). Comparative analysis of phytoconstituents and caffeine levels of acacia nilotica (subalata) and coffea arabica varieties. IOSR J. Pharm. Biol. Sci., 11(2), 23-27.

15. Tran, N., Mir, A., Mallik, D., Sinha, A., Nayar, S. \& Webster, T. J. (2010). Bactericidal effect of iron oxide nanoparticles on Staphylococcus aureus. Int. J. Nanomedicine, 5, 277-283, https://doi.org/10.2147/ijn. s9220.

16. The National Committee for Clinical Laboratory Standards (NCCLS). (2002). Reference method for broth dilution antifungal susceptibility testing of yeasts: Approved standard; Second edition. NCCLS document M27-A2. Wayne, PA: NCCLS.

17. Teoh, Y. P., Don, M. M. \& Ujang, S. (2011). Media selection for mycelia growth, antifungal activity against wood-degrading fungi, and GC-MS study by Pycnoporus sanguineus. BioRes., 6(3), 2719-2731, https://doi. org/10.15376/biores.6.3.2719-2731.

18. Sathishkumar, G., Logeshwaran, V., Sarathbabu, S., Pradeep K. J., Jayaraj, M., Rajkuberan, C., Senthilkumar, N. \& Sivaramakrishnan, S. (2018). Green synthesis of magnetic $\mathrm{Fe}_{3} \mathrm{O}_{4}$ nanoparticle using Couroupita guianensis Aubl. Fruit extract for their antibactierial and cytotoxicity activities. Artif. Cells Nanomed. Biotechnol., 46(3), 589-598, https://doi. org/10.1080/21691401.2017.1332635.

19. Srivastav, S. K. \& Gajbhiye, N. S. (2012). Low temperature synthesis, structural, optical and magnetic properties of bismuth ferrite nanoparticles. J. Am. Ceram. Soc., 95(11), 3678-3682, https://doi.org/10.1111/j.15512916.2012.05411.x.

20. Pavani, T., Rao, K. V., Chakra C. H. S. \& Prabhu, Y. T. (2015). A facile method of synthesizing Ayurvedic medicine: Lauha bhasma (iron oxide nanoparticles) and its characterization. Sch. Acad. J. Pharm., 4(1), 51-53. 
21. Zhang, X., Niu, Y., Meng, X., Li, Y. \& Zhao, J. (2013). Structural evolution and characteristics of the phase transformations between $\alpha-\mathrm{Fe}_{2} \mathrm{O}_{3}, \mathrm{Fe}_{3} \mathrm{O}_{4}$ and $\gamma-\mathrm{Fe}_{2} \mathrm{O}_{3}$ nanoparticles under reducing and oxidizing atmospheres. CrystEngComm, 15, 8166-8172, https://doi.org/10.1039/C3CE41269E.

22. Awwad, A. M., Albiss, B. A. \& Salem, N. M. (2015). Antibacterial activity of synthesized copper oxide nanoparticles using Malva sylvestris leaf extract. Sikkim Manipal University Medical Journal, 2(1), 91-98, https:// www.researchgate.net/publication/307534456.

23. Teoh, Y. P. (2014). Production of anti-fungal agent by Schizophyllum commune against wood-degrading fungi of rubberwood. PhD thesis, Universiti Sains Malaysia, Pulau Pinang, Malaysia.

24. Naseem, T.\&Farrukh,M.A.(2015). Antibacterial activity of green synthesis of iron nanoparticles using Lawsonia inermis and Gardenia jasminoides leaves extract. J. Chem., 912342, https://doi.org/10.1155/2015/912342.

25. Behera, S. S., Patra, J. K., Pramanik, K., Panda, N. \& Thatoi, H. (2012). Characterization and evaluation of antibacterial activities of chemically synthesized iron oxide nanoparticles. World J. Nano Sci. Eng., 2(4), 196200, https://doi.org/10.4236/wjnse.2012.24026.

26. Mahdy, S. A., Raheed, Q. J. \& Kalaichelvan, P. T. (2012). Antimicrobial activity of zero-valent iron nanoparticles. Int. J. Mod. Eng. Res., 2, 578-581, Retrieved from https://citeseerx.ist.psu.edu/viewdoc/ download?doi $=10.1 .1 .450 .3205 \&$ rep $=$ rep1\&type $=$ pdf.

27. Lee, C., Kim, J. Y., Lee, W. I., Nelson, K. L., Yoon, J. \& Sedlak, D. L. (2008). Bactericidal effect of zero-valent iron nanoparticles on Escherichia coli. Environ. Sci. Technol., 42, 4927-4933, https://doi.org/10.1021/ es800408u. 